\title{
Highly Variable Dietary RNAi Sensitivity Among Coleoptera
}

\author{
Jonathan Willow ${ }^{1,2 *}$ and Eve Veromann ${ }^{1}$ \\ ${ }^{1}$ Chair of Plant Health, Institute of Agricultural and Environmental Sciences, Estonian University of Life Sciences, Tartu, \\ Estonia, ${ }^{2}$ Department of Plants and Crops, Laboratory of Agrozoology, Faculty of Bioscience Engineering, Ghent University, \\ Ghent, Belgium
}

Many herbivorous beetles (Order Coleoptera) contribute to serious losses in crop yields and forest trees, and plant biotechnology solutions are being developed with the hope of limiting these losses. Due to the unprecedented target-specificity of double-stranded RNA (dsRNA), and its utility in inducing RNA interference (RNAi) when consumed by target pest species, dsRNA-based plant biotechnology approaches represent the cutting edge of current pesticide research and development. We review dietary RNAi studies in coleopterans and discuss prospects and future directions regarding RNAi-based management of coleopteran plant pests. Herein, we also provide a balanced overview of existing studies in order to provide an accurate re-assessment of dietary RNAi sensitivity in coleopterans, despite the limitations to the existing body of scientific literature. We further

OPEN ACCESS

Edited by:

Jeremy Bruton Sweet, Sweet Environmental Consultants, United Kingdom

Reviewed by: Luc Swevers, National Centre of Scientific Research

Demokritos, Greece

${ }^{*}$ Correspondence: Jonathan Willow jonathan@emu.ee

Specialty section: This article was submitted to Plant Biotechnology,

a section of the journal Frontiers in Plant Science

Received: 07 October 2021 Accepted: 18 November 2021 Published: 07 December 2021

Citation:

Willow J and Veromann E (2021) Highly Variable Dietary RNAi Sensitivity Among Coleoptera.

Front. Plant Sci. 12:790816. doi: 10.3389/fp/s.2021.790816 discuss impediments to our understanding of RNAi sensitivity in this important insect order and identify critical future directions for research in this area, with an emphasis on using plant biotechnology approaches.

Keywords: RNA interference, dsRNA, plant biotechnology, beetle, biological variability, biopesticide, insecticide, dietary RNAi

\section{INTRODUCTION}

Of all arthropod orders, the insect order Coleoptera (beetles) contains the greatest number of described species (Stork, 2018). While many beetle species perform valuable agroecological services, such as biological control and pollination (Rader et al., 2016), others can be highly damaging pests of crops and forest trees. The most common solution to managing important coleopteran plant pests globally is the use of synthetic broad-spectrum insecticides. In addition, organic and other ecologically intensified farming systems use environmentally sound management techniques, such as enhancing conservation biological control, creating refuge areas, mixed cropping systems, and the use of cover crops. Plant protection biotechnologies are increasingly considered for combating coleopteran pest pressure, and such technologies include the use of Bacillus thuringiensis toxins and double-stranded RNA (dsRNA).

dsRNA currently represents the most species-specific approach to managing plant pests, given its nucleotide sequence-specific mode of action that relies on base-pairing between applied exogenous dsRNA (processed in vivo into segments 20-24 nucleotides in length) and complementary endogenous messenger RNA (mRNA). Generally, the complementarity of 21 consecutive nucleotides initiates the cleaving of the base-paired mRNA region, preventing translation of the targeted mRNA, a process known as RNA interference (RNAi). This unprecedented 
target-specificity is the basis for RNAi's promise for biosafety to non-target organisms, and in turn the increasing interest in developing RNA-based biotechnology solutions to address plant protection. RNAi-based plant protection biotechnologies that have made significant progress include host-induced gene silencing (HIGS) technology via the use of transgenic cultivars containing RNAi traits, and spray-induced gene silencing (SIGS) technology via exogenous application of dsRNA to plants. Open-field RNAi-based management of western corn rootworm (Diabrotica virgifera) will commence in the United States in 2022 (followed by Canada in 2023), via the HIGS approach of consuming the tissues of the maize cultivar SmartStax PRO (Bayer, Germany), containing an RNAi-inducing trait. The biotechnology company GreenLight Biosciences (United States) is currently developing a SIGS approach against this pest Colorado potato beetle (Leptinotarsa decemlineata).

Investigations into RNAi-based management of coleopteran plant pests began with Baum et al. (2007), who demonstrated high dietary RNAi sensitivity (e.g., achieving target phenotype post-consumption of low amounts of dsRNA) in both $D$. virgifera and $L$. decemlineata. Since then, there has been an ongoing narrative, in RNAi-based insect management literature, that most coleopterans are sensitive to dietary RNAi. While this sensitivity has been clearly demonstrated in some coleopteran plant pests, many coleopteran species that have been examined show little to moderate sensitivity to dietary RNAi, and the vast majority of Order Coleoptera has not been examined. For the coleopteran species that have been examined, no overview of RNAi efficacy between and within coleopteran taxa has yet been presented to the scientific community.

Our timely review provides a balanced overview of dietary RNAi studies conducted on coleopteran species and discusses impediments to our knowledge regarding the overall prospects for RNAi-based biotechnology solution in the management of coleopteran plant pests. Given the upcoming introduction of insect RNAi technology to the American plant protection marketplace via the cultivation of transgenic maize containing an RNAi trait against $D$. virgifera, together with the role of coleopteran herbivores in causing significant damage globally to crops and forest trees, this represents a timely and critical re-assessment of our current state of knowledge. Our assessment is standardized to examine studies using non-formulated dsRNA (e.g., without the use of nanoparticles that enhance cellular uptake and systemic RNAi) to provide a reasonable comparison within and between coleopterans thus far studied. Biotechnologies considered in the present review include transgenic RNAi plants, "naked" dsRNA applications and bacterially expressed dsRNA.

\section{OBSERVED RNAi SENSITIVITIES IN COLEOPTERA}

\section{Family Chrysomelidae}

Leaf beetles (Family Chrysomelidae) feed on a variety of plant tissues, and all chrysomelid species are fully herbivorous, many being serious crop pests. Several studies have shown that dietary
RNAi sensitivity is quite high in the two chrysomelids D. virgifera (Baum et al., 2007; Bolognesi et al., 2012; Bachman et al., 2013; Miyata et al., 2014; Niu et al., 2017; Vélez et al., 2020) and L. decemlineata (Baum et al., 2007; Miguel and Scott, 2015; Cappelle et al., 2016; Spit et al., 2017; Máximo et al., 2020; Petek et al., 2020; Ren et al., 2021). Notably, Petek et al. (2020) demonstrated, in a small field study in Slovenia, that treating plants with water containing $0.01 \mu \mathrm{g}$ dsRNA/ $\mu$ l significantly reduced $L$. decemlineata infestation in the field. This study was a landmark, as it suggests potential for dsRNA spray-based management of a major agricultural pest in open-field conditions, by mixing dsRNA with water alone.

Another chrysomelid, the mustard leaf beetle (Phaedon cochleariae), was recently examined for its potential as a screening model for coleopteran pests, and this species also demonstrated high RNAi sensitivity, with a strong lethal phenotype observed via consumption of leaf disks treated with water containing $0.025 \mu \mathrm{g}$ dsRNA/ $\mu$ l (Mehlhorn et al., 2021). Zhang et al. (2019) demonstrated that painting a thin layer of water, containing a diluted suspension of dsRNA-expressing bacteria, on fresh willow leaves resulted in approximately 40 and $80 \%$ mortality of Plagiodera versicolora larvae after 2 and 7 days, respectively. More recently, Xu et al. (2021) painted poplar leaves with dsRNA to a concentration of $8 \mathrm{ng} / \mathrm{cm}^{2}$ and demonstrated $100 \%$ mortality in $P$. versicolora larvae within 5-7 days, depending on target gene. Notably, the authors observed over $60 \%$ mortality after 3 days of feeding on dsRNA targeting actin (see Supplementary Material in Xu et al., 2021). These studies with P. versicolora, together with that of Máximo et al. (2020), who observed effective $L$. decemlineata mortality after 2 days, suggest that RNAi can work in a timely manner in some coleopterans, perhaps in particular chrysomelids of the subfamily Chrysomelinae. Furthermore, studies performed in chrysomelids collectively suggest high dietary RNAi efficacy via various sources of dsRNA consumption (e.g., RNAi cultivar., naked dsRNA, and bacterially expressed dsRNA).

\section{Family Tenebrionidae}

Darkling beetles (Family Tenebrionidae), while occupying a diverse array of ecological niches, consist of several important plant product pests, particularly in cereal and flour silos, as well as other stored food products. To our knowledge, the only tenebrionid species examined using dietary RNAi is the red flour beetle (Tribolium castaneum), a pest of global importance, and the existing data on dietary RNAi efficacy in T. castaneum are variable. Whyard et al. (2009) reported, after 7 days of dietary exposure, an $\mathrm{LC}_{50}$ of $0.0025 \mu \mathrm{g} \mathrm{dsRNA} / \mathrm{mg}$ diet, and Laudani et al. (2017) reported approximately $30 \%$ mortality after 3 days of feeding on $0.015 \mu \mathrm{g}$ dsRNA/mg diet, both studies being in contrast to Cao et al. (2018) who reported far more delayed RNAi in T. castaneum via feeding on 17- and 33-fold higher concentrations than those used by Laudani et al. (2017). Showing intermediate efficacy relative to the abovementioned studies, Abd El Halim et al. (2016) demonstrated 50\% mortality after 6 days of feeding on $0.1 \mu \mathrm{g}$ dsRNA/mg diet. As each study, with the exception of Abd El Halim et al. (2016), targeted vATPase components, these contrasting results clearly indicate a need for more investigations 
in order to solidify any conclusions regarding dietary RNAi efficacy in T. castaneum. Furthermore, expanding dietary RNAi studies to consider other important tenebrionid pests represent a critical route toward future biotechnological solutions to protect plant-based foods globally.

\section{Family Coccinellidae}

Lady beetles (Family Coccinellidae) are an important group of coleopterans, regarding plant protection, due to different species' roles as predators of crop pests (e.g., Hippodamia convergens, Coleomegilla maculata, and Coccinella septempunctata), invasive pests that outcompete beneficial lady beetles (e.g., Harmonia axyridis), and herbivorous pests that can be highly damaging to crop yields (e.g., Henosepilachna vigintioctopunctata). Targeting the same gene in four lady beetle species $(H$. convergens, $H$. axyridis, $C$. maculata, and C. septempunctata), Pan et al. (2020) observed approximately $80,5,60$, and $70 \%$ mortality, respectively. These results indicate that dietary RNAi efficacy may be highly variable between coccinellid species. Furthermore, the concentration of dsRNA in the diet provided to coccinellids during the abovementioned study $(4 \mu \mathrm{g}$ dsRNA/ $\mu \mathrm{l})$ was rather high in relation to what would be realistically applicable in RNAi-based plant protection, suggesting the need to re-evaluate the dietary RNAi susceptibility of some of these more RNAi-sensitive species, using more economically feasible dsRNA concentrations.

Lü et al. (2020a,b, 2021a,b) and Guo et al. (2021) examined RNAi efficacy via oral delivery of dsRNAs targeting various genes in the 28-spotted potato ladybird (H. vigintioctopunctata). Lü et al. (2020b) observed approximately 60\% mortality (8 days, target gene Snf7) and 70-85\% mortality (10 days, targeting eight different coatomer components) via feeding on leaves treated with dsRNA at a concentration of $0.005 \mu \mathrm{g}$ dsRNA/ $\mu$ l. Guo et al. (2021) observed nearly complete mortality after 7 days (target gene $v A T P a s e$ ) of feeding on leaves treated with dsRNA at a concentration of $0.01 \mu \mathrm{g}$ dsRNA/ $\mu$ l. These studies by Lü et al. (2020a,b, 2021a,b) and Guo et al. (2021) additionally examined dietary RNAi efficacy in $H$. vigintioctopunctata firstand third-instar larvae and adults, using bacterially expressed dsRNA and demonstrated higher and faster RNAi efficacy in larvae compared to adults. Finally, Ren et al. (2021) observed significant growth retardation in $H$. vigintioctopunctata via consumption of transgenic potato plants. While sufficient data now exist for $H$. vigintioctopunctata, indicating its sensitivity to dietary RNAi, especially when fed leaves treated with low dsRNA concentrations (both naked and bacterially expressed), more data are required with regard to other coccinellid species, both pests and beneficials.

\section{Family Curculionidae}

True weevils (Family Curculionidae) make up the largest coleopteran family. Many species are plant pests, and several have been studied with regard to their sensitivity to dietary RNAi. Christiaens et al. (2016) demonstrated, in the sweetpotato weevil Cylas brunneus, 46-49\% mortality (depending on target gene) after 7 days of feeding on artificial diet containing dsRNA at a concentration of $0.01 \mu \mathrm{g}$ dsRNA/ $\mu \mathrm{l}$. C. brunneus mortality reached $85-89 \%$ after 14 days. Prentice et al. (2019) demonstrated, in the sweetpotato weevil Cylas puncticollis, that 7 days of feeding on artificial diet treated with dsRNA (target gene Snf7) at a concentration of $0.01 \mu \mathrm{g} \mathrm{dsRNA} / \mu \mathrm{l}$ resulted in $36 \%$ mortality after 14 days. Wu et al. (2019) observed no effect on survival of pepper weevil (Anthonomus eugenii) after dietary exposure to pepper coated with dsRNA (target genes Snf7 and vATPase A) at a concentration of $0.3 \mu \mathrm{g}$ dsRNA/ $\mu$ l. Pinheiro et al. (2020) observed between 43 and $93 \%$ mortality in the Sri Lanka weevil (Myllocerus undecimpustulatus), depending on the target gene. However, as mortality was only monitored after 26 days (dsRNA treatments were administered for 20 days), there remain critical unknowns with regard to timeliness of RNAi-induced mortality. Salvador et al. (2021) reported that 14 days of dietary exposure, using artificial diet overlaid with treatment solutions containing $0.2 \mu \mathrm{g}$ dsRNA/ $\mu$ l, resulted in $40-60 \%$ mortality in cotton boll weevil (Anthonomus grandis) larvae, and $10-30 \%$ mortality in adults, percent mortality depending on target gene in both life stages.

Finally, Kyre et al. (2019) provided a sucrose-based liquid diet containing $10 \mu \mathrm{g}$ dsRNA/ $\mu \mathrm{l}$ to southern pine beetle (Dendroctonus frontalis) adults. While this dsRNA concentration is unrealistically high in relation to what is feasible for RNAibased plant protection, they nevertheless provided a proof-ofconcept that this forest pest species is susceptible to dietary RNAi. Here, RNAi-induced mortality ranged from completely ineffective to $100 \%$ mortality, depending on target gene. Taking these data on $D$. frontalis, and further examining this species' RNAi sensitivity when exposed to field-realistic concentrations of dietary dsRNA, represents a vital step toward understanding the potential for controlling this forest pest. More broadly, curculionids clearly show variable susceptibility to dietary RNAi. Curculionidae being the largest family in Order Coleoptera, with many curculionid species being detrimental to economically important plant species globally, much more research is needed in order to conclude any patterns regarding RNAi sensitivity in this family. Further studies with curculionids would benefit from including multiple sources of dsRNA consumption (e.g., RNAi cultivar., bacterially expressed dsRNA), as thus far studies in weevils have only examined naked dsRNA in artificial diet.

\section{Family Nitidulidae}

Sap beetles (Family Nitidulidae) represent an important family containing several very important plant pest species. The first nitidulid to be examined for sensitivity to dietary RNAi was the small hive beetle (Aethina tumida), a facilitative pest of flowering plant species due to its status as a major pest of honey bees (honey bees being important for sexual reproduction of many flowering plant species). Powell et al. (2017) reported 73-93\% adult $A$. tumida emergence (depending on target gene), compared $100 \%$ adult emergence in control group, after 6 days of dietary exposure to $33 \mu \mathrm{g}$ dsRNA/g artificial diet.

The only other nitidulid to be examined thus far via dietary RNAi is the pollen beetle Brassicogethes aeneus. Knorr et al. (2018) observed at least $90 \%$ adult B. aeneus mortality after 14 days, in all four target gene treatments examined, after dietary 
exposure to water containing $1 \mu \mathrm{g} \mathrm{dsRNA} / \mu \mathrm{l}$ followed by continuous uptake of dsRNA in artificial diet containing $500 \mathrm{ng} / \mathrm{cm}^{2}$. Willow et al. (2020, 2021a,b,c) examined RNAi sensitivity in B. aeneus via multiple field-relevant routes of exposure, and in both adults and larvae. A SIGS approach to achieving RNAi-induced mortality in $B$. aeneus, via feeding on dsRNA-treated oilseed rape buds and anthers, leads to variable success in achieving a lethal phenotype in this pest species. Most notably, high concentrations of $2.5-5 \mu \mathrm{g}$ dsRNA/ $\mu$ l proved effective after 3 days of feeding on dsRNA-treated anthers, while these concentrations and a lower concentration of $0.5 \mu \mathrm{g} \mathrm{dsRNA} / \mu \mathrm{l}$ showed significantly greater efficacy when dsRNA-treated anthers were provided for 17 days (Willow et al., 2021b). This is an important finding due to constant development and senescence of oilseed rape flowers, making successive sprays over the growing season a potential necessity for implementing a SIGS approach. In contrast, 3 days of feeding on treated oilseed rape buds, even when using a dsRNA concentration as high as $5 \mu \mathrm{g}$ dsRNA/ $\mu$ l, showed negligible effect on B. aeneus adult survival (Willow et al., 2020).

The abovementioned studies indicate that both $A$. tumida and $B$. aeneus demonstrate little to moderate susceptibility to dietary RNAi. Further studies examining field-relevant dsRNA concentrations in a SIGS approach may provide evidence necessary to make conclusions regarding RNAi susceptibility in these two important pest species. The significantly enhanced RNAi efficacy from chronic dsRNA feeding, in B. aeneus (Willow et al., 2021b), also suggests potentially important benefits of developing RNAi cultivars to managing $B$. aeneus or other pests showing similar differences in RNAi efficacy between short-term and chronic dsRNA feeding. Furthermore, other economically important nitidulids (e.g., Stelidota geminata and Carpophilus spp.) should be examined, in order for us to understand more about the potential for implementing RNAi to manage nitidulid pests.

\section{Families Buprestidae and Cerambycidae}

Jewel beetles (Family Buprestidae) and longhorn beetles (Family Cerambycidae) consist of herbivorous species that feed on the tissues on roots, stems, and leaves of various herbaceous and woody plants. Some species are wood-borers that are highly damaging to forest trees. The only buprestid to be examined for dietary RNAi susceptibility is emerald ash borer (Agrilus planipennis). Rodrigues et al. (2017) exposed A. planipennis larvae to dietary dsRNA (in vitro synthesized) in sucrose solution for 4 days, and mortality of $A$. planipennis was monitored at 10 days. The authors observed 30,35, and 78\% larval mortality associated with 1,6 , and $10 \mu \mathrm{g}$ dsRNA/ $\mu$ l treatments, respectively. More recently, Leelesh and Rieske (2020) demonstrated 47-69\% mortality (depending on target gene) in A. planipennis larvae fed bacterially expressed dsRNA (at approximately 100 bacterial cells/nl).

The only cerambycid to be examined for dietary RNAi susceptibility is Asain long-horned beetle (Anoplophora glabripennis). Dhandapani et al. (2020a) exposed A. glabripennis larvae to dietary dsRNA (in vitro synthesized) in sucrose solution for 3 days, and mortality was monitored up to 10 days. The authors observed (depending on target gene) 17-25\%, 50-67\%, and 75-90\% larval mortality associated with force-fed doses of 2,5 , and $10 \mu \mathrm{g}$ dsRNA/day, respectively. Another study reported approximately $20 \%$ mortality, after 20 days, in both larval and adult A. glabripennis that were fed $15 \mu \mathrm{g}$ dsRNA/day for 3 days (see Supplementary Material in Dhandapani et al., 2020b).

As the concentrations/doses used in the abovementioned buprestid and cerambycid studies are all above what is realistic for pest management, together with the fact that these woodboring species would not be exposed to dsRNA through sucrose solutions or dsRNA-expressing bacteria, more studies should be conducted using field-realistic concentrations, and via fieldrelevant exposure routes (e.g., vascular cambium and wood). Furthermore, studies examining dietary RNAi susceptibility in wood-boring beetles may benefit greatly from the development of RNAi cultivars of the relevant tree species, for use in experiments; this is important, as a HIGS approach may represent the most economic and effective RNAi technique for managing forest tree pests.

\section{CONCLUSION AND FUTURE DIRECTIONS}

Few families in the order Coleoptera have been examined for dietary RNAi efficacy. Furthermore, within each family examined, few species are represented in the existing dietary RNAi literature. Surprisingly, our findings from this review indicate that less than half of the coleopteran species thus far examined for dietary RNAi efficacy are sensitive to dietary RNAi. While methods and concentrations used are variable within chrysomelid studies, all chrysomelid species thus far examined seem to show high sensitivity to dietary RNAi, a possible reason for the ongoing narrative that most coleopterans have high sensitivity to dietary RNAi. The species considered here to be insensitive to dietary RNAi have either demonstrated very little RNAi-induced mortality, or effective lethality of dsRNA has been observed for these species only when using unrealistically high concentrations of dsRNA. Considering that these studies are conducted after dsRNA-microinjection bioassays have already taken place, indicating what would theoretically be the most appropriate gene to target for inducing a lethal phenotype upon dsRNA ingestion, the dietary RNAi-insensitivity of more than half of all coleopterans examined is alarming. As some studies have indicated the role of dsRNases in lowering, limiting, or preventing dietary RNAi in certain coleopteran species (Almeida Garcia et al., 2017; Spit et al., 2017; Prentice et al., 2019; Peng et al., 2020), this potential limiting factor should be investigated in other coleopteran species for which dietary RNAi sensitivity is observed to be low. Furthermore, numerous studies have only examined routes of exposure that are not applicable to real-world pest management.

Source of dsRNA consumption represents an important variable when determining dietary RNAi sensitivity in any organism. Other than the three dsRNA-sensitive species $D$. virgifera (Baum et al., 2007; Vélez et al., 2020), L. decemilineata (Ren et al., 2021), and H. vigintioctopunctata (Ren et al., 2021), no other coleopteran has been examined for RNAi cultivarbased management efficacy. Such studies would contribute much to forwarding our knowledge regarding the prospects for using transgenic approaches to RNAi-based management of coleopteran 
plant pests. Most studies in coleopterans examine potential for RNAi-based management via the use of naked dsRNA in artificial diets. This has allowed us to make general comparisons, regarding dietary RNAi efficacy, across and between taxa. The use of naked dsRNA also enables accurate reporting of dsRNA doses/concentrations examined. Some studies reported in our review examine dietary RNAi efficacy via the use of bacterially expressed dsRNA. In the case of the lady beetle $H$. vigintioctopunctata, dietary RNAi efficacies are similar whether using naked dsRNA or bacterially expressed dsRNA.

Other than the need to examine a greater diversity of pest species within the coleopteran families already discussed in the present review, there are numerous other important coleopteran taxa deserving of attention with regard to potential susceptibility to dietary RNAi. These include not only pest species, but also species that are important for directly providing ecosystem services (e.g., biological control, soil decomposition, and pollination), or species that play more facilitative roles in maintaining ecosystem biodiversity (e.g., those which are important food sources for higher trophic levels). Understanding dietary RNAi sensitivity in these beneficial coleopterans should be of great interest due to the concern for safeguarding non-target organisms. Furthermore, as co-formulating dsRNA with various types of nanoparticles can enhance dsRNA stability and RNAi efficacy in various insects (Pugsley et al., 2021), thereby making such formulations vital for SIGS approaches to plant protection, the use of different dsRNA-nanoparticle complexes continues to represent a critical avenue of investigation in both pest and beneficial coleopterans.

Finally, dsRNA resistance has been demonstrated in vivo via selective breeding in both $D$. virgifera (Khajuria et al., 2018) and L. decemlineata (Mishra et al., 2021), which is of great concern RNAi-based management of coleopteran pests. Yoon et al. (2018) observed that the dsRNA binding protein Staufen isoform C (stauC) is present in 24 of the 32 beetle genomes/transcriptomes they analyzed. The authors subsequently demonstrated stauC mRNA was significantly less expressed in an RNAi-resistant L. decemlineata cell line, and that in these cells, processing of dsRNA into small interfering RNAs was reduced by more than $80 \%$ compared to a susceptible L. decemlineata cell line. While the abovementioned study also suggests stauC downregulation as a catalyst for RNAi resistance in $D$. virgifera and $T$. castaneum, stauC's presence in only three-fourths of the coleopteran species bioinformatically analyzed

\section{REFERENCES}

Abd El Halim, H. M., Alshukri, B. M. H., Ahmad, M. S., Nakasu, E. Y. T., Awwad, M. H., Salama, E. M., et al. (2016). RNAi-mediated knockdown of the voltage gated sodium ion channel $\mathrm{TcNa}_{\mathrm{v}}$ causes mortality in Tribolium castaneum. Sci. Rep. 6:29301. doi: 10.1038/srep29301

Almeida Garcia, R., Lima Pepino Macedo, L., Cabral do Nascimento, D., Gillet, F.-X., Moreira-Pinto, C. E., Faheem, M., et al. (2017). Nucleases as a barrier to gene silencing in the cotton boll weevil, Anthonomus grandis. PLoS One 12:e0189600. doi: 10.1371/journal.pone.0189600

Bachman, P. M., Bolognesi, R., Moar, W. J., Mueller, G. M., Paradise, M. S., Ramaseshadri, P., et al. (2013). Characterization of the spectrum of insecticidal activity of a double-stranded RNA with targeted activity against western in the study suggests a diversity of RNAi resistance potential and/or mechanisms within Coleoptera. RNAi being a promising and biosafe technology for plant protection, these findings on RNAi resistance support the need for investigations into precise RNAi resistance mechanisms among different coleopteran taxa.

RNAi technology will likely play a major role in plant protection against coleopteran insects, given the current momentum in both research and development for the use of this biotechnology to protect both crop yields and forest trees. For RNAi-sensitive chrysomelid species, both HIGS and SIGS approaches are in development for the plant biotechnology marketplace. HIGS, through the development and use of RNAi cultivars that constantly produce target-specific dsRNA, may be the most appropriate method of dsRNA delivery when dealing with plant pests that only show effective dietary RNAi when chronically exposed to dsRNA. This transgenic approach is also likely an appropriate direction for managing tree pests, as successful RNAi-based management of these pests seems more likely if the targetspecific dsRNA is constantly produced in the tree tissues, as opposed to forest management's reliance on a future of accurately timed trunk injections. That being said, it remains critical to examine possibilities for using both transgenic and non-transgenic approaches to managing coleopteran plant pest species.

\section{AUTHOR CONTRIBUTIONS}

JW conceived the manuscript and wrote the original draft. All authors made comments or suggestions toward revising the original draft and approved the final version of the manuscript.

\section{FUNDING}

The review was funded by the Personal Research Funding project no. PRG1056 of the Estonian Research Council.

\section{ACKNOWLEDGMENTS}

We thank Ana Isabel Silva for useful comments during all stages of manuscript preparation, and Clauvis Nji Tizi Taning for fruitful conversation.

corn rootworm (Diabrotica virgifera virgifera LeConte). Trans. Res. 22, 1207-1222. doi: 10.1007/s11248-013-9716-5

Baum, J. A., Bogaert, T., Clinton, W., Heck, G. R., Feldmann, P., Ilagan, O., et al. (2007). Control of coleopteran insect pests through RNA interference. Nat. Biotechnol. 25, 1322-1326. doi: 10.1038/nbt1359

Bolognesi, R., Ramaseshadri, P., Anderson, J., Bachman, P., Clinton, W., Flannagan, R., et al. (2012). Characterizing the mechanism of action of doubloe-stranded RNA activity against western corn rootworm (Diabrotica virgifera virgifera LeConte). PLoS One 7:e47534. doi: 10.1371/journal. pone.0047534

Cao, M., Gatehouse, J. A., and Fitches, E. C. (2018). A systematic study of RNAi effects and dsRNA stability in Tribolium castaneum and Acyrthosiphon pisum, following injection and ingestion of analogous dsRNAs. Int. J. Mol. Sci. 19:1079. doi: 10.3390/ijms19041079 
Cappelle, K., de Oliveira, C. F. R., Van Eynde, B., Christiaens, O., and Smagghe, G. (2016). The involvement of clathrin-mediated endocytosis and two Sid-1-like transmembrane proteins in double-stranded RNA uptake in the Colorado potato beetle midgut. Insect Mol. Biol. 25, 315-323. doi: 10.1111/imb.12222

Christiaens, O., Prentice, K., Pertry, I., Ghislain, M., Bailey, A., Niblett, C., et al. (2016). RNA interference: a promising biopesticide strategy against the African sweetpotato weevil Cylas brunneus. Sci. Rep. 6:38836. doi: 10.1038/srep38836

Dhandapani, R. K., Duan, J. J., and Palli, S. R. (2020a). Orally delivered dsRNA induces knockdown of target genes and mortality in the Asian long-horned beetle, Anoplophora glabripennis. Arch. Insect Biochem. Physiol. 104:e21679. doi: 10.1002/arch.21679

Dhandapani, R. K., Gurusamy, D., Duan, J. J., and Palli, S. R. (2020b). RNAi for management of Asian long-horned beetle, Anoplophora glabripennis: identification of target genes. J. Pest. Sci. 93, 823-832. doi: 10.1007/ s10340-020-01197-8

Guo, W., Guo, M., Yang, C., Liu, Z., Chen, S., Lü, J., et al. (2021). RNA interference-mediated silencing of vATPase subunits A and E affect survival and development of the 28-spotted ladybeetle, Henosepilachna vigintioctopunctata. Insect Sci. [Epub ahead of print]. doi: 10.1111/1744-7917.12899

Khajuria, C., Ivashuta, S., Wiggins, E., Flagel, L., Moar, W., Pleau, M., et al. (2018). Development and characterization of the first dsRNA-resistant insect population from western corn rootworm, Diabrotica virgifera virgifera LeConte. PLOS One 13:e0197059. doi: 10.1371/journal.pone.0197059

Knorr, E., Fishilevich, E., Tenbusch, L., Frey, M. L. F., Rangasamy, M., Billion, A., et al. (2018). Gene silencing in Tribolium castaneum as a tool for the targeted identification of candidate RNAi targets in crop pests. Sci. Rep. 8, 2061-2015. doi: 10.1038/s41598-018-20416-y

Kyre, B. R., Rodrigues, T. B., and Rieske, L. K. (2019). RNA interference and validation of reference genes for gene expression analyses using qPCR in southern pine beetle, Dendroctonus frontalis. Sci. Rep. 9:5640. doi: 10.1038/ s41598-019-42072-6

Laudani, F., Strano, C. P., Edwards, M. G., Malacrinò, A., Campolo, O., Halim, H. M. A. E., et al. (2017). RNAi-mediated gene silencing in Rhynchophorus ferrugineus (Oliver) (Coleoptera: Curculionidae). Open Life Sci. 12, 214-222. doi: 10.1515/biol-2017-0025

Leelesh, R. S., and Rieske, L. K. (2020). Oral ingestion of bacterially expressed dsRNA can silence genes and cause mortality in a highly invasive, treekilling pest, the emerald ash borer. Insects 11:440. doi: 10.3390/insects11070440

Lü, J., Guo, W., Chen, S., Guo, M., Qiu, B., Yang, C., et al. (2020b). Feeding delivery of dsHvSnf7 is a promising method for management of the pest Henosepilachna vigintioctopunctata (Coleoptera: Coccinellidae). Insects 11:34. doi: 10.3390/insects11010034

Lü, J., Guo, M., Chen, S., Noland, J. E., Guo, W., Sang, W., et al. (2020a). Double-stranded RNA targeting vATPase B reveals a potential target for pest management of Henosepilachna vigintioctopunctata. Pestic. Biochem. Physiol. 165:104555. doi: 10.1016/j.pestbp.2020.104555

Lü, J., Liu, Z.-Q., Guo, W., Guo, M.-J., Chen, S.-M., Yang, C.-X., et al. (2021a). Oral delivery of dsHvlwr is a feasible method for managing the pest Henosepilachna vigintioctopunctata (Coleoptera: Coccinellidae). Insect Sci. 28, 509-520. doi: 10.1111/1744-7917.12784

Lü, J., Yang, C., Liu, Z., Vélez, A. M., Guo, M., Chen, S., et al. (2021b). Dietary RNAi toxicity assay suggests $\alpha$ and $\gamma$ subunits of HvCOPI as novel molecular targets for Henosepilachna vigintioctopunctata, an emerging coccinellid pest. J. Pest. Sci. 94, 1473-1486. doi: 10.1007/s10340-021-01350-X

Máximo, W. P. F., Howell, J. L., Mogilicherla, K., Basij, M., Chereddy, S. C. R. R., and Palli, S. R. (2020). Inhibitor of apoptosis is an effective target gene for RNAi-mediated control of Colorado potato beetle, Leptinotarsa decemlineata. Arch. Insect Biochem. Physiol. 104:e21685. doi: 10.1002/arch.21685

Mehlhorn, S., Ulrich, J., Baden, C. U., Buer, B., Maiwald, F., Lueke, B., et al. (2021). The mustard leaf beetle, Phaedon cochleariae, as a screening model for exogenous RNAi-based control of coleopteran pests. Pestic. Biochem. Phys. 176:104870. doi: 10.1016/j.pestbp.2021.104870

Miguel, K. S., and Scott, J. G. (2015). The next generation of insecticides: dsRNA is stable as a foliar-applied insecticide. Pest Manag. Sci. 72, 801-809. doi: $10.1002 /$ ps.4056

Mishra, S., Dee, J., Moar, W., Dufner-Beattie, J., Baum, J., Dias, N. P., et al. (2021). Selection for high levels of resistance to double-stranded RNA (dsRNA) in Colorado potato beetle (Leptinotarsa decemlineata say) using non-transgenic foliar delivery. Sci. Rep. 11:6523. doi: 10.1038/ s41598-021-85876-1

Miyata, K., Ramaseshadri, P., Zhang, Y., Segers, G., Bolognesi, R., Tomoyasu, Y., et al. (2014). Establishing an in vivo assay system to identify components involved in environmental RNA interference in the western corn rootworm. PLoS One 9:e101661. doi: 10.1371/journal.pone.0101661

Niu, X., Kassa, A., Hu, X., Robeson, J., McMahon, M., Richtman, N. M., et al. (2017). Control of Western corn rootworm (Diabrotica virgifera virgifera) reproduction through plant-mediated RNA interference. Sci. Rep. 7:12591. doi: 10.1038/s41598-017-12638-3

Pan, H., Yang, X., Romeis, J., Siegfried, B. D., and Zhou, X. (2020). Dietary RNAi toxicity assay exhibits differential responses to ingested dsRNAs among lady beetles. Pest Manag. Sci. 76, 3606-3614. doi: 10.1002/ps.5894

Peng, Y., Wang, K., Chen, J., Wang, J., Zhang, H., Ze, L., et al. (2020). Identification of a double-stranded RNA-degrading nuclease influencing both ingestion and injection RNA interference efficiency in the red flour beetle Tribolium castaneum. Insect Biochem. Mol. Biol. 125:103440. doi: 10.1016/j. ibmb.2020.103440

Petek, M., Coll, A., Ferenc, R., Razinger, J., and Gruden, K. (2020). Validating the potential of double-stranded RNA targeting Colorado potato beetle mesh gene in laboratory and field trials. Front. Plant Sci. 11:1250. doi: 10.3389/ fpls.2020.01250

Pinheiro, D. H., Taylor, C. E., Wu, K., and Siegfried, B. D. (2020). Delivery of gene-specific dsRNA by microinjection and feeding induces RNAi response in Sri Lanka weevil, Myllocerus undecimpustulatus undatus Marshall. Pest Manag. Sci. 76, 936-943. doi: 10.1002/ps.5601

Powell, M. E., Bradish, H. M., Gatehouse, J. A., and Fitches, E. C. (2017). Systemic RNAi in the small hive beetle Aethina tumida Murray (Coleoptera: Nitidulidae), a serious pest of the European honey bee Apis mellifera. Pest Manag. Sci. 73, 53-63. doi: 10.1002/ps.4365

Prentice, K., Smagghe, G., Gheysen, G., and Christiaens, O. (2019). Nuclease activity decreases the RNAi response in the sweetpotato weevil Cylas puncticollis. Insect Biochem. Mol. Biol. 110, 80-89. doi: 10.1016/j. ibmb.2019.04.001

Pugsley, C. E., Isaac, R. E., Warren, N. J., and Cayre, O. J. (2021). Recent advances in engineered nanoparticles for RNAi-mediated crop protection against insect pests. Front. Agron. 3:652981. doi: 10.3389/ fagro.2021.652981

Rader, R., Bartomeus, I., Garibaldi, L. A., Garratt, M. P. D., Howlett, B. G., Winfree, R., et al. (2016). Non-bee insects are important contributors to global crop pollination. Proc. Natl. Acad. Sci. U. S. A. 113, 146-151. doi: $10.1073 /$ pnas. 1517092112

Ren, B., Cao, J., He, Y., Yang, S., and Zhang, J. (2021). Assessment on effects of transplastomic potato plants expressing Colorado potato beetle $\beta$-actin double-stranded RNAs for three non-target pests. Pestic. Biochem. Phys. 178:104909. doi: 10.1016/j.pestbp.2021.104909

Rodrigues, T. B., Rieske, L. K., Duan, J., and J., Mogilicherla, K., and Palli, S. R., (2017). Development of RNAi method for screening candidate genes to control emerald ash borer, Agrilus planipennis. Sci. Rep. 7:7379. doi: 10.1038/ s41598-017-07605-X

Salvador, R., Niz, J. M., Nakaya, P. A., Pedarros, A., and Hopp, H. E. (2021). Midgut genes knockdown by oral dsRNA administration produces a lethal effect on cotton boll weevil. Neotrop. Entomol. 50, 121-128. doi: 10.1007/ s13744-020-00819-1

Spit, J., Philips, A., Wynant, N., Santos, D., Plaetinck, G., and Vanden Broeck, J. (2017). Knockdown of nuclease activity in the gut enhances RNAi efficiency in the Colorado potato beetle, Leptinotarsa decemlineata, but not in the desert locust, Schistocerca gregaria. Insect Biochem. Mol. Biol. 81, 103-116. doi: 10.1016/j.ibmb.2017.01.004

Stork, N. E. (2018). How many species of insects and other terrestrial arthropods are there on earth? Annu. Rev. Entomol. 63, 31-45. doi: 10.1146/annurevento-020117-043348

Vélez, A. M., Fishilevich, E., Rangasamy, M., Khajuria, C., McCaskill, D. G., Pereira, A. E., et al. (2020). Control of western corn rootworm via RNAi traits in maize: lethal and sublethal effects of Sec23 dsRNA. Pest Manag. Sci. 76, 1500-1512. doi: 10.1002/ps.5666

Whyard, S., Singh, A. D., and Wong, S. (2009). Ingested double-stranded RNAs can act as species-specific insecticides. Insect Biochem. Mol. Biol. 39, 824-832. doi: $10.1016 /$ j.ibmb.2009.09.007 
Willow, J., Soonvald, L., Sulg, S., Kaasik, R., Silva, A. I., Taning, C. N. T., et al. (2020). First evidence of bud feeding-induced RNAi in a crop pest via exogenous application of dsRNA. Insects 11:769. doi: 10.3390/ insects11110769

Willow, J., Soonvald, L., Sulg, S., Kaasik, R., Silva, A. I., Taning, C. N. T., et al. (2021a). Anther-feeding-induced RNAi in Brassicogethes aeneus larvae. Front. Agron. 3:633120. doi: 10.3389/fagro.2021.633120

Willow, J., Soonvald, L., Sulg, S., Kaasik, R., Silva, A. I., Taning, C. N. T., et al. (2021b). RNAi efficacy is enhanced by chronic dsRNA feeding in pollen beetle. Commun. Biol. 4:444. doi: 10.1038/s42003-021-01975-9

Willow, J., Sulg, S., Taning, C. N. T., Silva, A. I., Christiaens, O., Kaasik, R., et al. (2021c). Targeting a coatomer protein complex-I gene via RNA interference results in effective lethality in the pollen beetle Brassicogethes aeneus. J. Pest. Sci. 94, 703-712. doi: 10.1007/s10340-020-01288-6

Wu, K., Taylor, C. E., Pinheiro, D. H., Skelley, L. H., McAuslane, H. J., and Siegfried, B. D. (2019). Lethal RNA interference response in the pepper weevil. J. Appl. Entomol. 143, 699-705. doi: 10.1111/jen.12644

Xu, L., Xu, S., Sun, L., Zhang, Y., Luo, J., Bock, R., et al. (2021). Synergistic action of the gut microbiota in environmental RNA interference in a leaf beetle. Microbiome 9:98. doi: 10.1186/s40168-021-01066-1

Yoon, J.-S., Mogilicherla, K., Gurusamy, D., Chen, X., Chereddy, S. C. R. R., and Palli, S. R. (2018). Double-stranded RNA binding protein, Staufen, is required for the initiation of RNAi in coleopteran insects. Proc. Natl. Acad. Sci. U. S. A. 115, 8334-8339. doi: 10.1073/pnas.1809381115

Zhang, Y., Xu, L., Li, S., and Zhang, J. (2019). Bacteria-mediated RNA interference for management of Plagiodera versicolora (Coleoptera: Chrysomelidae). Insects 10:415. doi: 10.3390/insects10120415

Conflict of Interest: The authors declare that the research was conducted in the absence of any commercial or financial relationships that could be construed as a potential conflict of interest.

Publisher's Note: All claims expressed in this article are solely those of the authors and do not necessarily represent those of their affiliated organizations, or those of the publisher, the editors and the reviewers. Any product that may be evaluated in this article, or claim that may be made by its manufacturer, is not guaranteed or endorsed by the publisher.

Copyright (C) 2021 Willow and Veromann. This is an open-access article distributed under the terms of the Creative Commons Attribution License (CC BY). The use, distribution or reproduction in other forums is permitted, provided the original author(s) and the copyright owner(s) are credited and that the original publication in this journal is cited, in accordance with accepted academic practice. No use, distribution or reproduction is permitted which does not comply with these terms. 